\section{IMPROVED AIRWAY HEALING AFTER LUNG TRANSPLANTATION}

\author{
An analysis of 348 \\ bronchial anastomoses
}

We evaluated various clinical factors to identify predictors of airway complication after lung transplantation. Two hundred twenty-nine consecutive single ( $n=110$ ) and bilateral $(n=119)$ lung transplants were done between September 1988 and August 1994. These 348 bronchial anastomoses were retrospectively analyzed. Airway complication that necessitated clinical intervention affected 33 anastomoses $(9.5 \%)$ in 29 patients $(12.8 \%)$. Satisfactory healing was achieved in 22 of these patients by conservative therapy such as one or a combination of dilation, stent, and laser. There were five deaths $(2.2 \%)$ attributable to airway complications. One patient had an early postoperative death unrelated to airway complication and one patient has a recalcitrant bronchus intermedius stricture. Complication occurred more often in single-lung than in bilateral lung transplants $(16 / 110,14.4 \%$, versus $17 / 238,7.1 \% ; p<0.05)$. The use of a mattress suture $(21 / 153,13.7 \%)$ was associated with more frequent complications than was simple interrupted suture $(8 / 122,6.6 \%)$ or figure-of-eight suture $(4 / 73,5.5 \%)(p<0.05)$. For patients in whom airway complications subsequently developed, the duration of postoperative mechanical ventilation was greater than that for those in whom an airway complication did not develop. The prevalence of airway complications as our program evolved was evaluated by separating the 229 transplants into three groups: phase I, the first 77 transplants; phase $I$, the next 76 transplants; and phase III, the most recent 76 transplants. The airway complication rate per anastomosis was significantly lower in phase III (5/126, $4.0 \%)$ than in phase I $(12 / 110,10.9 \% ; p<0.05)$ and phase II $(16 / 112,14.3 \%$; $p<0.01$ ). The majority of airway complications are successfully treated and rarely fatal. The recent reduction in prevalence of airway complications is likely a result of better maintenance immunosuppression and rejection surveillance. (J ThoraC CARDIOvasC SuRG 1995;110:1424-33)

Hiroshi Date, $\mathrm{MD}^{\mathrm{a}}$ (by invitation), Elbert P. Trulock, $\mathrm{MD}^{\mathrm{b}}$ (by invitation), Joseph M. Arcidi, MD ${ }^{a}$ (by invitation), Sudhir Sundaresan, MD, ${ }^{a}$

Joel D. Cooper, MD, ${ }^{a}$ and G. Alexander Patterson, MD, ${ }^{a}$ St. Louis, Mo.
In the early days of clinical lung transplantation, dehiscence of the bronchial anastomosis was a frequent source of mortality. ${ }^{1}$ Improvements in patient selection, lung allograft preservation, sur-

From the Division of Cardiothoracic Surgery ${ }^{a}$ and Respiratory and Critical Care Medicine, ${ }^{b}$ Washington University School of Medicine, St. Louis, Mo.

Read at the Seventy-fifth Annual Meeting of The American Association for Thoracic Surgery, Boston, Mass., April 23-26, 1995.

Address for reprints: G. Alexander Patterson, MD, Division of Cardiothoracic Surgery, Washington University School of Medicine, One Barnes Hospital Plaza, Suite 3108 Queeny Tower, St. Louis, MO 63110.

Copyright $(0) 1995$ by Mosby-Year Book, Inc.

$0022-5223 / 95 \$ 5.00+0 \quad \mathbf{1 2 / 6 / 6 7 3 8 5}$ gical technique, postoperative care, and immunosuppression have reduced the prevalence of airway complications. Experienced centers have recently reported the prevalence of airway complications to be in the range of $7 \%$ to $14 \% .^{2,3}$ In our center airway complications represent an infrequent source of mortality. ${ }^{4}$ The optimum techniques of bronchial anastomosis and of perioperative and postoperative treatment of transplant recipients remain controversial and vary from one center to another. This retrospective review of our experience was conducted to evaluate various clinical factors and identify those that might be associated with the development of bronchial anastomotic complications in a group of single (SLT) and bilateral sequential (BLT) lung transplant recipients. 


\section{Patients and methods}

Between September 1988 and August 1994, 229 SLTs $(n=110)$ and BLTs $(n=119)$ were done in 226 patients at Barnes Hospital. These 348 anastomoses were retrospectively reviewed and evaluated in December 1994 with a minimum follow-up of 120 days. En bloc double-lung transplants $(n=8)$ were not included in this study.

Donor lungs were harvested by the technique we have previously described. ${ }^{5}$ All donors were pretreated with systemic heparin and the pulmonary artery bed was flushed with modified Euro-Collins solution after prostaglandin $\mathrm{E}_{1}(500 \mu \mathrm{g})$ administration directly into the pulmonary artery.

All transplants were done with the use of previously described techniques. ${ }^{6,7}$ The donor bronchus was shortened to two rings proximal to the upper lobe takeoff. In our most recent 217 cases anastomoses were conducted in the following sequence: bronchus, pulmonary artery, left atrium. In the first 12 SLTs in our experience, the bronchial anastomosis was done last. The technique used for bronchial anastomosis has evolved with time. Until September 1991, an end-to-end anastomosis with simple interrupted 4-0 Vicryl polyglactin 910 sutures (Ethicon, Inc., Somerville, N.J.) was done in most cases. We then adopted a telescoping technique in most cases whenever the difference in bronchial size between the donor and the recipient was significant (see latter part of Results section). The anastomosis was constructed with 4-0 Prolene polypropylene (Ethicon) or polydioxanone (PDS, Ethicon) sutures as described by Griffith and associates ${ }^{3}$ or with a figure-of-eight technique as described by Calhoon and colleagues. ${ }^{7}$ We continued to use end-to-end anastomoses with simple interrupted or figure-of-eight sutures when donor and recipient bronchi were of an equal size and for a small-caliber left bronchial anastomosis. Direct bronchial artery revascularization was not used. Some form of bronchial anastomotic coverage was used in all but four anastomoses. Early in our experience a pedicled flap of omentum was used routinely. Pericardial fat was later used in a small number of cases but the majority of anastomoses were covered with donor and recipient peribronchial fat and nodal tissue. Patients received methylprednisolone 500 to $1000 \mathrm{mg}$ intravenously at the time of reperfusion.

Standard immunosuppression consisted of azathioprine (2 mg/kg), cyclosporine, steroid, and antilymphocyte antibody. Cyclosporine was given as a continuous infusion ( 3 to $6 \mathrm{mg} / \mathrm{hr}$ ) in the early postoperative period, followed by enteral administration when tolerated. The dose was adjusted to obtain a blood level in the high therapeutic to slightly supratherapeutic range. Until 1991 routine therapy with steroids was withheld during the early postoperative period. Subsequently methylprednisolone $0.5 \mathrm{mg} / \mathrm{kg}$ per day intravenously was administered for 3 days, followed by oral prednisone $0.5 \mathrm{mg} / \mathrm{kg}$ per day. Induction cytolytic therapy was used in most patients. The first six patients received OKT3. Toxicity of this agent prompted routine use of Minnesota antilymphocyte globulin (15 $\mathrm{mg} / \mathrm{kg}$ per day intravenously) until July 1992 when that agent was no longer available. After a 6-month interval when no cytolytic therapy was used for induction, ATGAM lymphocyte immunoglobulin/antithymocyte globulin (Up- john Co., Kalamazoo, Mich.) $15 \mathrm{mg} / \mathrm{kg}$ per day intravenously was used routinely.

Flexible fiberoptic bronchoscopy was frequently used to monitor donor airway viability and integrity of the bronchial anastomosis. Patients routinely underwent initial bronchoscopic evaluation before they were taken from the operating room and again immediately before extubation. Routine surveillance bronchoscopies with bronchoalveolar lavage and transbronchial lung biopsies were done at 2 to 3 weeks and 2, 3, 6, and 12 months, and annually thereafter. Bronchoscopy was done on other occasions dictated by clinical parameters such as dyspnea, hypoxemia, decline in pulmonary function test result, radiographic infiltrate, or unexplained fever.

For purposes of this review, an airway complication was defined as a finding of significant dehiscence that necessitated extended chest tube drainage or other surgical intervention or a finding of stenosis or malacia that necessitated dilation, debridement, laser therapy, or stent placement. Partial dehiscence, mucosal necrosis, or slough detected by bronchoscopy was not considered an airway complication when satisfactory healing occurred without further intervention.

Various clinical factors were evaluated to identify predictors of airway complication. Factors evaluated were recipient factors (age, sex, diagnosis, previous preoperative steroid history, current preoperative steroid use), donor factors (age, sex, arterial oxygen tension $\left[\mathrm{PaO}_{2}\right]$ at fraction of inspired oxygen $\left[\mathrm{F}_{\mathrm{i}} \mathrm{O}_{2}\right] 100 \%$ and $5 \mathrm{~cm} \mathrm{H}_{2} \mathrm{O}$ positive end-expiratory pressure, ischemic time), operative factors (type of transplant, side of transplant, requirement for cardiopulmonary bypass, type of bronchial anastomosis, suture technique, suture material, type of wrapping), and postoperative factors $\left(\mathrm{PaO}_{2}\right.$ at $\mathrm{F}_{\mathrm{i}} \mathrm{O}_{2} 100 \%$, mean systemic pressure, mean arterial pressure, cardiac output, peak airway pressure: all measured on arrival in the intensive care unit). Other postoperative factors included used of continuous intravenous prostaglandin $E_{1}$ infusion during the first 24 postoperative hours, percentage of allograft perfusion measured by quantitative ventilation-perfusion nuclear scintigraphy within the first 12 postoperative hours, duration of mechanical ventilation, early maintenance steroid use, number of 3-day bolus methylprednisolone course given as therapy for suspected acute rejection within the first 30 days, total dose of bolus methylprednisolone given within the first 30 days, the first day of bolus methylprednisolone given, type of induction cytolytic therapy, transbronchial biopsy-proven A2 or greater acute rejection within the first 30 days, cytomegalovirus status, and biopsy-proven cytomegalovirus pneumonia within the first 90 days.

The prevalence of airway complications during different stages of our program was evaluated by separating the 229 transplants into three groups: phase I, the first 77 transplants; phase II, the next 76 transplants; and phase III, the most recent 76 transplants. All parameters noted previously were evaluated among the three phases.

Predictors of airway complications were analyzed by multivariate analysis. Significance was sought among three phases with use of a $\chi^{2}$ test for nonparametric data and analysis of variance and the Tukey honest significant difference multiple comparisons procedure for parametric 
Table I. Recipient preoperative factors

\begin{tabular}{lccc}
\hline \multicolumn{1}{c}{ Factors } & $\begin{array}{c}\text { Group I: no } \\
\text { complication } \\
(n=315)\end{array}$ & $\begin{array}{c}\text { Group II: } \\
\text { complication } \\
(n=33)\end{array}$ & $\begin{array}{c}p \\
\text { Value }\end{array}$ \\
\hline Age (yr) & $42.8 \pm 11.7$ & $44.6 \pm 12.1$ & NS \\
Sex & & & NS \\
$\quad$ Male & $157(49.8)$ & $15(45.5)$ & \\
$\quad$ Female & $158(50.2)$ & $18(54.5)$ & \\
Diagnosis & & & NS \\
$\quad$ Obstructive & $176(55.9)$ & $19(57.6)$ & \\
$\quad$ Restrictive & $27(8.6)$ & $4(12.1)$ & \\
$\quad$ Septic & $72(22.9)$ & $6(18.2)$ & \\
$\quad$ PVD & $40(12.7)$ & $4(12.1)$ & \\
Remote steroid history & & & NS \\
$\quad$ Yes & $221(70.2)$ & $23(69.7)$ & \\
$\quad$ No & $94(29.8)$ & $10(30.3)$ & \\
Preop. steroid use & & & NS \\
$\quad$ Yes & $84(26.7)$ & $12(36.4)$ & \\
$\quad$ No & $231(73.3)$ & $21(63.6)$ & \\
\hline
\end{tabular}

Values in parentheses indicate percentage. NS, Not significant; PVD, primary pulmonary hypertension, Eisenmenger's syndrome.

Table II. Donor factors

\begin{tabular}{lccc}
\hline \multicolumn{1}{c}{ Factors } & $\begin{array}{c}\text { Group I: no } \\
\text { complication } \\
(n=315)\end{array}$ & $\begin{array}{c}\text { Group II: } \\
\text { complication } \\
(n=33)\end{array}$ & $\begin{array}{c}p \\
\text { Value }\end{array}$ \\
\hline Age (yr) & $27.8 \pm 10.9$ & $24.7 \pm 11.8$ & NS \\
Sex & & & NS \\
$\quad$ Male & $221(70.2)$ & $27(81.8)$ & \\
Female & $94(29.8)$ & $6(18.2)$ & \\
$\mathrm{PaO}_{2}$ (mm Hg) & $470 \pm 80$ & $494 \pm 63$ & NS \\
Ischemic time (min) & $314 \pm 93$ & $291 \pm 102$ & NS \\
\hline
\end{tabular}

Values in parentheses indicate percentage. $\mathrm{PaO}_{2}$ was measured with $\mathrm{F}_{\mathrm{i}} \mathrm{O}_{2}$ $100 \%, 5 \mathrm{~cm} \mathrm{H}_{2} \mathrm{O}$ positive end-expiratory pressure. NS, Not significant.

data. Data are expressed as mean plus or minus 1 standard deviation. Statistical significance was accepted at the $95 \%$ confidence level, $p<0.05$.

\section{Results}

Airway complication. Significant dehiscence affected 15 anastomoses in 12 patients $15.7 \pm 10.7$ days ( 4 to 38 days) after transplantation. Five patients, including two patients who underwent retransplantation, died of this complication. In another five patients, chest tube or mediastinal tube placement, or both, to achieve complete reexpansion of the lung permitted satisfactory closure of the leak. Although a stricture ultimately developed in one patient, it was successfully managed by subsequent dilation. In one patient, a silicone-rubber stent was placed 26 days after transplantation with a satisfactory result. In one patient, sudden death of unknown cause occurred 3 days after chest tube placement.

Significant stenosis occurred in 18 anastomoses among 17 patients $105.2 \pm 86.7$ days ( 24 to 385 days) after transplantation. All but one case were successfully managed by conservative therapy such as one or a combination of dilation (17 patients), stent (11 patients), and laser (4 patients). One bilateral lung recipient had complete obstruction of the bronchus intermedius, which could not be adequately treated.

In summary, airway complications that necessitated clinical intervention occurred in 29 patients $(12.8 \%)$ and 33 anastomoses $(9.5 \%)$. Conservative therapy resulted in excellent improvement in 22 patients. There were five deaths $(2.2 \%)$ attributable to airway complications.

Evaluation of clinical factors. Various clinical factors were evaluated by comparing the cases of the 315 anastomoses that healed without complication (group I) with the cases of the 33 anastomoses that necessitated clinical intervention (group II).

Recipient factors (Table I) and donor factors (Table II) were not significantly different between the two groups.

Data from analysis of operative factors are shown in Table III. Anastomotic complications occurred more often in SLT than in BLT $(16 / 110,14.4 \%$, versus $17 / 238,7.1 \% ; p<0.05$ ). Mattress suture $(21 / 153,13.7 \%)$ was associated with more frequent complications than was simple interrupted suture $(8 / 122,6.0 \%)$ or figure-of-eight suture $(4 / 73,5.5 \%)$ $(p<0.05)$. No correlation was found between transplant side, use of cardiopulmonary bypass, anastomosis type (end-to-end versus telescope), suture material, or type of wrapping and the subsequent development of an airway complication.

Postoperative factors in the intensive care unit (ICU) are summarized in Table IV. Patients in whom airway complications subsequently developed had required longer postoperative mechanical ventilation than those without airway complications $(12.9 \pm 18.4$ days versus $5.5 \pm 20.5$ days, $p<0.01)$. Among 289 anastomoses subjected to mechanical ventilation for less than 7 days, $22(7.6 \%)$ complications were observed. In contrast, among 59 anastomoses subjected to mechanical ventilation for longer than 7 days, $11(18.6 \%)$ complications were noted $(p<0.01) . \mathrm{PaO}_{2}$, mean arterial pressure, mean pulmonary artery pressure, cardiac output, and peak airway pressure were not significantly different between the two groups. Use of prostaglandin $\mathrm{E}_{1}$ and 
the percentage of pulmonary perfusion to the anastomosis side did not correlate with the subsequent development of airway complications.

Other postoperative factors regarding immunosuppression, rejection, and cytomegalovirus infection are shown in Table $\mathrm{V}$. There was no significant difference between the two groups with respect to any of these factors.

Prevalence of airway complications with evolution of transplant program. The prevalence of airway complications in different phases of our series is summarized in Table VI. The airway complication rate was significantly reduced to $4.0 \%$ in phase III from $10.9 \%$ in phase I and $14.3 \%$ in phase II.

We speculated that this recent decrease in airway complications might be a result of various changes in technical and clinical management practices over time. We therefore reevaluated all the clinical factors listed in Tables I through V. Factors that changed significantly among the three phases are shown in Table VII. All other factors were not significantly different among the three phases.

Significant technical change occurred between phase I and phase II. In phase I, the standard technique was an end-to-end anastomosis with simple interrupted 4-0 Vicryl polyglactin 910 sutures followed by bronchial omentopexy. In phase II, a telescoping anastomosis with modified mattress 4-0 PDS polydioxanone sutures followed by wrapping with peribronchial nodal tissue was commonly used. No significant technical change was made between phase II and phase III except that omentopexy was completely abandoned in phase III. Preoperative steroid use and postoperative prostaglandin $E_{1}$ infusion were significantly increased in phase II compared with their use in phase I. However, there was no difference between phase II and phase III.

Postoperative immunosuppression and rejection monitoring, were changed significantly between phase II and phase III. Low-dose corticosteroid administration from day 1 along with induction cytolytic therapy with antithymocyte globulin was routinely used in phase III. Rejection therapy by bolus injection of methylprednisolone was mainly based on histologic (transbronchial lung biopsy) evidence rather than empiric clinical diagnosis (such as fever, cough, shortness of breath, decrease of $\mathrm{PaO}_{2}$ ) in phase III. As a result, course of methylprednisolone and total dose of methylprednisolone given within 30 days were significantly decreased
Table III. Operative factors

\begin{tabular}{|c|c|c|}
\hline Factors & $\begin{array}{l}\text { Airway } \\
\text { complication } \\
\text { rate }\end{array}$ & $\begin{array}{c}p \\
\text { Value }\end{array}$ \\
\hline Operation type & & $<0.05$ \\
\hline SLT & $16 / 110(14.4)$ & \\
\hline BLT & $17 / 238(7.1)$ & \\
\hline Side & & NS \\
\hline Right & $17 / 174(9.8)$ & \\
\hline Left & $16 / 174(9.2)$ & \\
\hline $\mathrm{CPB}$ & & NS \\
\hline Yes & $12 / 102(11.8)$ & \\
\hline No & $21 / 246(8.5)$ & \\
\hline Anastomosis type & & NS \\
\hline End-to-end & $11 / 158(7.0)$ & \\
\hline Telescope & $22 / 190(11.6)$ & \\
\hline Donor into recipient & $13 / 102(12.8)$ & \\
\hline Recipient into donor & $9 / 88(10.2)$ & \\
\hline Suture technique & & $<0.05$ \\
\hline Simple & $8 / 122(6.6)$ & \\
\hline Figure-of-eight & $4 / 73(5.5)$ & \\
\hline Mattress & $21 / 153(13.7)$ & \\
\hline Suture material & & NS \\
\hline PDS polydioxanone & $20 / 243(8.2)$ & \\
\hline Vicryl polyglactin 910 & $10 / 93(10.8)$ & \\
\hline Prolene polypropylene & $3 / 12(25.0)$ & \\
\hline Wrapping & & NS \\
\hline Omentum & $10 / 112(8.9)$ & \\
\hline Peribronchial tissue & $17 / 194(8.8)$ & \\
\hline Pericardial fat & $5 / 36(13.9)$ & \\
\hline Intercostal muscle & $0 / 2(0.0)$ & \\
\hline None & $1 / 4(25.0)$ & \\
\hline
\end{tabular}

Values in parentheses indicate percentage. $N S$, Not significant; $C P B$, cardiopulmonary bypass.

Table IV. Postoperative factors (ICU)

\begin{tabular}{lccc}
\hline \multicolumn{1}{c}{ Factors } & $\begin{array}{c}\text { Group l: no } \\
\text { complication } \\
(n=315)\end{array}$ & $\begin{array}{c}\text { Group II: } \\
\text { complication } \\
(n=33)\end{array}$ & $\begin{array}{c}p \\
\text { Value }\end{array}$ \\
\hline $\mathrm{PaO}_{2}(\mathrm{~mm} \mathrm{Hg})$ & $346 \pm 153$ & $317 \pm 152$ & $\mathrm{NS}$ \\
$\mathrm{BP}(\mathrm{mm} \mathrm{Hg})$ & $79.6 \pm 11.0$ & $83.9 \pm 10.6$ & $\mathrm{NS}$ \\
$\mathrm{PAP}(\mathrm{mm} \mathrm{Hg})$ & $23.3 \pm 6.4$ & $24.5 \pm 5.1$ & $\mathrm{NS}$ \\
$\mathrm{CO}(\mathrm{L} / \mathrm{min})$ & $4.7 \pm 1.4$ & $4.7 \pm 1.0$ & $\mathrm{NS}$ \\
$\mathrm{PGE}{ }_{1}$ & & & $\mathrm{NS}$ \\
$\quad \mathrm{Yes}$ & $214(67.9)$ & $25(75.8)$ & \\
$\quad \mathrm{No}$ & $101(32.1)$ & $8(24.2)$ & \\
Perfusion scan (to & $58.0 \pm 20.5$ & $64.9 \pm 17.5$ & $\mathrm{NS}$ \\
$\quad$ anastomosis) (\%) & & & \\
Peak airway pressure & $31.1 \pm 5.7$ & $31.2 \pm 6.3$ & $\mathrm{NS}$ \\
$\quad$ (cm $\left.\mathrm{H}_{2} \mathrm{O}\right)$ & & & \\
Mechanical ventilation & $5.5 \pm 9.9$ & $12.9 \pm 18.4$ & $<0.01$ \\
$\quad$ (days) & & &
\end{tabular}

Values in parentheses indicate percentage. $\mathrm{PaO}_{2}$, arterial pressure, pulmonary artery pressure, cardiac output, and peak airway pressure were measured 1 hour after the patient was admitted to ICU. $P a O_{2}$, Arterial oxygen tension with $\mathrm{F}_{8} \mathrm{O}_{2} 100 \%$; $N$, not significant; $B P$, mean arterial pressure; $P A P$, mean pulmonary artery pressure; $C O$, cardiac output; $P G E_{1}$, prostaglandin $\mathrm{E}_{1}$. 
Table V. Postoperative factors (immunosuppression, rejection, cytomegalovirus)

\begin{tabular}{lccc}
\hline \multicolumn{1}{c}{ Factors } & $\begin{array}{c}\text { Group I: no } \\
\text { complication } \\
(n=315)\end{array}$ & $\begin{array}{c}\text { Group II: } \\
\text { complication } \\
(n=33)\end{array}$ & $\begin{array}{c}p \\
\text { Value }\end{array}$ \\
\hline Postop. steroid use & & & NS \\
From day 1 & $173(54.9)$ & $19(57.6)$ & \\
From day 4-7 & $133(42.2)$ & $12(36.4)$ & \\
From day 21 & $9(2.9)$ & $2(6.1)$ & \\
Courses of MPD <30 days & $1.9 \pm 1.0$ & $1.9 \pm 1.1$ & NS \\
MPD given <30 days (gm) & $2.4 \pm 1.3$ & $2.6 \pm 1.5$ & NS \\
First bolus MPD (day) & $5.7 \pm 4.1$ & $4.6 \pm 2.8$ & NS \\
Cytolytic therapy & & & NS \\
ALG & $160(50.8)$ & $18(54.5)$ & \\
ATG & $128(40.6)$ & $6(18.2)$ & \\
OKT3 & $5(1.6)$ & $1(3.0)$ & \\
None & $22(7.0)$ & $8(24.2)$ & \\
A2 rejection or greater & & & NS \\
$<30$ days* & & & \\
Yes & $105(34.7)$ & $6(22.2)$ & \\
No & $197(65.2)$ & $21(77.8)$ & \\
Recipient/donor CMV status & & & NS \\
N/N & $62(19.7)$ & $5(15.2)$ & \\
P/N & $68(21.6)$ & $8(24.2)$ & \\
N/P & $91(28.9)$ & $9(27.3)$ & \\
P/P & $94(29.8)$ & $11(33.3)$ & \\
CMV pneumonia <90 days & & & NS \\
Yes & $108(37.5)$ & $6(26.1)$ & \\
No & $180(62.5)$ & $17(73.9)$ & \\
\hline
\end{tabular}

Values in parentheses indicate percentage. NS, Not significant; MPD, methylprednisolone (Upjohn); $A L G$, antilymphocyte globulin; $A T G$, antithymocyte globulin (Upjohn); OKT3, monoclonal antibody to the $\mathrm{CD} 3$ receptor on lymphocytes (Ortho Pharmaceutical Corp., Raritan, N.J.); $C M V$, cytomegalovirus; $N$, negative; $P$, positive.

*Data obtained from the patients who survived more than 30 days. $\dagger$ Data obtained from the patients who survived more than 90 days.

and the first bolus methylprednisolone dose was significantly delayed in phase III compared with that in phases I and II. Biopsy-proven A2 or greater rejection within the first 30 days was documented in more recipients in phase III than in phases I and II. This is because of the increase in biopsy procedures in phase III. The number of early transbronchial lung biopsies done was 67 in phase I, 104 in phase II, and 151 in phase III. The prevalence of A1 or greater rejection per biopsy procedure was unchanged among the three phases.

\section{Discussion}

Historically, poor bronchial healing was a major problem after lung transplantation. ${ }^{1}$ Without reconnection of the bronchial arterial circulation, airway viability is exclusively dependent on vascular supply by retrograde collateral flow from pulmonary to bronchial circulation. On the basis of favorable
Table VI. Chronologic prevalence of airway complications

\begin{tabular}{lccc}
\hline & Phase I & Phase II & Phase III \\
\hline Period & $1988.5-1991.7$ & $1991.8-1993.3$ & $1993.4-1994.8$ \\
No. of & 77 & 76 & 76 \\
$\quad$ transplants & & & \\
$\begin{array}{l}\text { Single/bilateral } \\
\text { No. of }\end{array}$ & $42 / 35$ & $40 / 36$ & $28 / 48^{*}$ \\
$\quad$ anastomoses & 110 & 112 & 126 \\
$\begin{array}{l}\text { Airway } \\
\quad \text { complication }\end{array}$ & $12 / 110(10.9)$ & $16 / 112(14.3)$ & $5 / 126(4.0) \dagger$ \\
\hline
\end{tabular}

Values in parentheses indicate percentage.

${ }^{*} p<0.05$ (versus phase I).

$\dagger p<0.05$ (versus phase I), $p<0.01$ (versus phase II).

results from a number of laboratory investigations, ${ }^{8-10}$ routine use of bronchial anastomotic omentopexy and avoidance of high-dose perioperative corticosteroids were thought to be key strategies for the first successful series of human lung transplants. ${ }^{11}$ However, recent studies have demonstrated that omentopexy is no longer essential and that modest early doses of postoperative corticosteroids do not impair airway healing. ${ }^{12-14}$ Alternative techniques such as telescoping anastomosis ${ }^{7}$ and direct bronchial revascularization ${ }^{15-17}$ have been reported with low rates of airway complication.

The ideal techniques of bronchial anastomosis and perioperative and postoperative treatment of transplant recipients are controversial and vary from one center to another. However, results appear similar even when different techniques are used. We have previously reported no difference in the prevalence of bronchial anastomotic complications from a concurrent series of patients who underwent transplantation at Washington University and the University of Toronto. ${ }^{13}$ Patients who underwent transplantation at the University of Toronto had mattressed anastomoses wrapped with local nodal tissue and received routine perioperative steroids. Patients who underwent transplantation at Washington University had end-to-end anastomoses wrapped in a pedicled flap omentum and did not receive routine early perioperative corticosteroids.

Having a large number of airway anastomoses for analysis, we were provided with an opportunity to review each of these factors in our own group of patients. The technique of bronchial anastomosis is undoubtedly important. Our experience did not show a significant difference in the airway complication rate between end-to-end and telescoped anastomoses. It should also be noted that there was no 
Table VII. Chronologic change of clinical factors

\begin{tabular}{|c|c|c|c|c|c|c|}
\hline \multirow[b]{2}{*}{ Factors } & \multirow[b]{2}{*}{ Phase I } & \multirow[b]{2}{*}{ Phase II } & \multirow[b]{2}{*}{ Phase III } & \multicolumn{3}{|c|}{$p$ Value } \\
\hline & & & & $I v_{s .} I I$ & $I$ vs. $I I I$ & II vs. III \\
\hline Preop. steroid use & & & & $<0.001$ & $<0.001$ & NS \\
\hline Yes & $6(7.8)$ & $22(28.9)$ & $32(42.1)$ & & & \\
\hline No & $71(92.2)$ & $54(71.1)$ & $44(57.9)$ & & & \\
\hline Anastomosis type ${ }^{*}$ & & & & $<0.001$ & $<0.001$ & NS \\
\hline End-to-end & $92(83.6)$ & $25(22.3)$ & $41(32.5)$ & & & \\
\hline Telescope & $18(16.4)$ & $87(77.7)$ & $85(67.5)$ & & & \\
\hline Suture technique* & & & & $<0.001$ & $<0.001$ & NS \\
\hline Simple & $88(80.0)$ & $18(16.1)$ & $16(12.7)$ & & & \\
\hline Figure-of-eight & $18(16.4)$ & $22(19.6)$ & $33(26.2)$ & & & \\
\hline Mattress & $4(3.6)$ & $72(64.3)$ & $77(61.1)$ & & & \\
\hline Suture material* & & & & $<0.001$ & $<0.001$ & NS \\
\hline PDS polydioxanone & $33(30.0)$ & $94(83.9)$ & $116(92.1)$ & & & \\
\hline Vicryl polyglactin 910 & $72(65.5)$ & $11(9.8)$ & $10(7.9)$ & & & \\
\hline Prolene polypropylene & $5(4.5)$ & $7(6.3)$ & $0(0.0)$ & & & \\
\hline Wrapping" & & & & $<0.001$ & $<0.001$ & $<0.001$ \\
\hline Omentum & $98(89.1)$ & $14(12.5)$ & $0(0 . \theta)$ & & & \\
\hline Peribronchial & $0(0.0)$ & $77(6.9)$ & $117(92.9)$ & & & \\
\hline Pericardial fat & $8(7.3)$ & $20(17.9)$ & $8(6.3)$ & & & \\
\hline Intercostal muscle & $2(1.8)$ & $0(0.0)$ & $0(0.0)$ & & & \\
\hline None & $2(1.8)$ & $1(0.9)$ & $1(0.8)$ & & & \\
\hline $\mathrm{PGE}_{1}$ & & & & $<0.001$ & $<0.001$ & NS \\
\hline Yes & $30(39.0)$ & $69(90.8)$ & $68(89.5)$ & & & \\
\hline No & $47(61.0)$ & $7(9.2)$ & $8(10.5)$ & & & \\
\hline Postop. steroid use & & & & $<0.001$ & $<0.001$ & $<0.001$ \\
\hline From day 1 & $3(3.9)$ & $48(63.2)$ & $68(89.5)$ & & & \\
\hline From day $4-7$ & $63(81.8)$ & $28(36.8)$ & $8(10.5)$ & & & \\
\hline From day 21 & $11(14.3)$ & $0(0.0)$ & $0(0.0)$ & & & \\
\hline Courses of MPD ( $<30$ days) & $2.2 \pm 0.9$ & $2.4 \pm 0.9$ & $1.5 \pm 0.9$ & NS & $<0.001$ & $<0.001$ \\
\hline MPD given $<30$ days $(\mathrm{gm})$ & $2.7 \pm 1.1$ & $2.9 \pm 1.3$ & $1.9 \pm 1.3$ & NS & $<0.005$ & $<0.001$ \\
\hline First bolus MPD (day) & $3.9 \pm 2.1$ & $4.3 \pm 2.1$ & $8.3 \pm 5.2$ & NS & $<0.001$ & $<0.001$ \\
\hline Cytolytic therapy & & & & $<0.001$ & $<0.001$ & $<0.001$ \\
\hline $\mathrm{ALG}$ & $69(89.6)$ & $53(69.7)$ & $0(0.0)$ & & & \\
\hline ATG & $0(0.0)$ & $9(11.8)$ & $74(97.4)$ & & & \\
\hline OKT3 & $6(7.8)$ & $0(0.0)$ & $0(0.0)$ & & & \\
\hline None & $2(2.6)$ & $14(18.4)$ & $2(2.6)$ & & & \\
\hline A2 rejection or greater $<30$ days & & & & NS & $<0.001$ & $<0.05$ \\
\hline Yes & $15(19.5)$ & $19(25.0)$ & $33(43.4)$ & & & \\
\hline No & $62(80.5)$ & $57(75.0)$ & $43(56.6)$ & & & \\
\hline
\end{tabular}

Values in parentheses indicate percentage. $N S$, Not significant; $P G E_{1}$, prostaglandin $\mathrm{E}_{1} ; M P D$, methylprednisolone; $A L G$, antilymphocyte globulin; $A T G$, antithymocyte globulin; $O K T 3$, monoclonal antibody to the CD3 receptor on lymphocytes.

*Data were obtained per anastomosis. All the other data were obtained per transplant.

difference whether the donor or recipient bronchus was intussuscepted. However, in this series the modified mattress suture used for a telescoping anastomosis was associated with a significantly greater rate of complications $(13.7 \%)$. Griffith and associate $\mathrm{d}^{3}$ has reported a similar complication rate $(12 \%)$ with use of this technique. When figure-ofeight suture was used for a telescoping anastomosis, the prevalence of airway complication was only $3.1 \%$. A modified mattress suture technique more readily achieves the desired intussusception and it avoids the potential creation of an obstructing flange of invaginated cartilage (Fig. 1). However, no strength is given between the overlapped cartilages. On the other hand, figure-of-eight suture gives firm strength between the overlapped cartilages although it is somewhat more difficult to achieve complete telescoping. Our current policy is as follows. When the bronchial size is equivalent, we use end-to-end anastomosis either by simple interrupted or figureof-eight sutures. For a small left bronchial anastomosis, we recommend simple interrupted suture. When the discrepancy in bronchial size is obvious, we use a telescoping technique either by figure-of- 
A
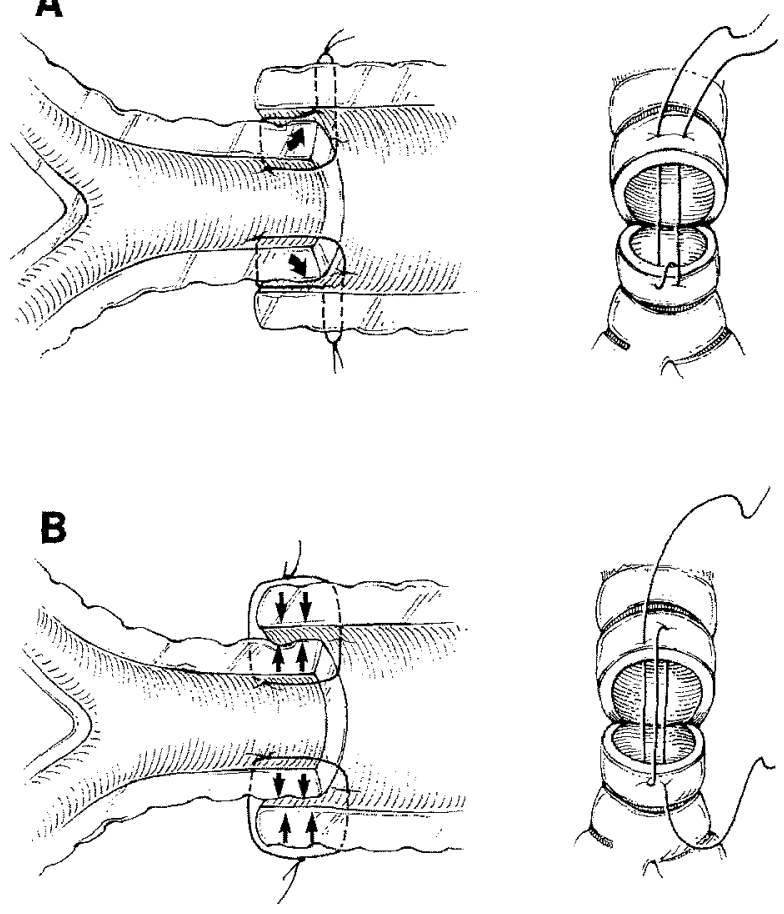

Fig. 1. A, Modified mattress suture. This technique holds rings of smaller airway to mucosal surface of larger airway to avoid potential for obstruction of flange of invaginated cartilage. However, no strength is given between two overlapped cartilages. B, Figure-of-eight suture. Firm strength is given between two overlapped cartilages although it is more difficult to achieve telescoping.

eight sutures when it is easy to achieve an intussusception or by a modified mattress suture technique when it is somewhat more difficult to achieve a telescoped result.

There was no difference in the airway complication rate among the types of bronchial wrapping. A prospective randomized study recently reported by Khaghani and colleagues ${ }^{18}$ has demonstrated that the prevalence of bronchial anastomotic complications after SLT is not affected by wrapping the anastomosis with either omentum or an internal mammary artery pedicle. Our current standard is wrapping the anastomosis with peribronchial nodal tissue because this is easy to achieve and eliminates any direct contact between the bronchial and pulmonary artery anastomosis.

It is interesting that none of the preoperative recipient factors evaluated was a predictor of airway complication. Although high-dose preoperative corticosteroid therapy may compromise bronchial healing, in our experience modest doses of preoperative prednisone do not affect airway integrity. Of note was that preoperative steroid use did not compromise airway integrity. This is the same conclusion that the San Antonio group has previously reported. ${ }^{7}$ Postoperative low-dose corticosteroid administration also did not increase airway complications, which confirms previous reports from the San Antonio $^{7}$ and Hannover ${ }^{12}$ groups.

It is interesting that airway complications were more commonly observed in SLT recipients. With two bronchial anastomoses, BLT has a twofold risk of airway complication compared with SLT. Furthermore, the transplanted lung receives more pulmonary artery perfusion than the native lung in SLT, whereas both lungs are equally perfused in BLT. Yet we have previously reported that patients receiving SLT because of pulmonary fibrosis and primary pulmonary hypertension have a longer requirement for mechanical ventilation as a result of allograft dysfunction. ${ }^{19}$ This may compromise collateral bronchial flow in these allografts in comparison with that in bilateral grafts in which allograft dysfunction is less commonly encountered. This may explain why SLT bronchial anastomoses were complicated more commonly than BLT anastomoses $(14.4 \%$ versus $7.1 \%)$. The relationship between allograft dysfunction and airway complications is further suggested by the fact that airway complications were much less commonly encountered in patients who received ventilator support for fewer than 7 days $(7.6 \%)$ in comparison with patients who received ventilator support longer than 7 days $(18.6 \%)$. We do not believe that mechanical ventilation in and of itself predisposes to an increased prevalence of airway complications. Indeed, Yokomise and colleagues ${ }^{20}$ have previously demonstrated that positive end-expiratory pressure augments retrograde collateral bronchial mucosal flow.

We acknowledge that this explanation for the differences in airway complications between SLT and BLT is speculative and impossible to confirm in this retrospective review. A more practical explanation is also available. It is possible that the bias of our transplant program directors was to treat airway problems in SLT recipients more aggressively than the same problems in BLT recipients. Although this may be true, the fact remains that clinically significant airway complications occurred more frequently in SLT than BLT recipients.

We observed a significant reduction in the airway complication rate to $4 \%$ during phase III. Major technical changes evolved between phase I and 
phase II but not between phase II and phase III as already described. Postoperative immunosuppression and rejection monitoring changed significantly between phase II and phase III. In phase III, low-dose corticosteroid administration from day 1 along with induction cytolytic therapy with antithymocyte globulin was routinely used and rejection therapy by bolus injection of methylprednisolone was mainly based on histologic rather than clinical diagnosis. These observations suggest that the recent improvement in airway healing is likely a result of better maintenance immunosuppression and rejection surveillance. Fujimura and associates ${ }^{21}$ have reported that lung allograft rejection is closely connected with wound healing of the bronchial anastomosis in canine lung transplantation. We think it is important to give timely but not excessive methylprednisolone for the treatment of acute rejection because pulmonary-to-bronchial collateral flow would be impaired by infection as well as by rejection.

The Harefield group ${ }^{15}$ and Bordeaux group ${ }^{16}$ have both reported successful bronchial artery revascularization for en bloc double-lung transplantation with tracheal anastomosis. Although we do not dispute the value of revascularization in that procedure, we remain unconvinced regarding its benefit in patients undergoing SLT and indeed BLT. Daly and McGregor ${ }^{17}$ from the Mayo Clinic have reported a small series of patients who underwent revascularization as part of a SLT procedure. We believe that this represents an additional technical challenge that is not necessary in the vast majority of patients and completely impractical in patients undergoing BLT. We await with interest the long-term follow-up results in these patients to determine whether such revascularization will have any impact on the ultimate development of bronchiolitis obliterans syndrome, as has been proposed.

Indeed, in the most recent 100 successive transplants conducted at our center, we have had only one death attributable to airway dehiscence. We believe that increasing experience, meticulous surgical technique, and rigorous postoperative care have significantly lessened the prevalence of airway complication after pulmonary transplantation.

We acknowledge the assistance of Mary Ann Kelly in preparation of the manuscript and statistical advice from Richard B. Schuessler, PhD.

\section{REFERENCES}

1. Veith FJ, Kamholz SL, Mollenkopf FP, Montefusco CM. Lung transplantation 1983. Transplantation 1983;35:271-8.

2. Shennib H, Massard G. Airway complication in lung transplantation. Ann Thorac Surg 1994;57:506-11.

3. Griffith BP, Magee MJ, Gonzalez IF, et al. Anastomotic pitfalls in lung transplantation. J THORAC CARDIOVASC Surg 1994;107:743-54.

4. Cooper JD, Patterson GA, Trulock EP, and the Washington University Lung Transplant Group. Results of 131 consecutive single and bilateral lung transplant recipients. J Thorac Cardiovasc SurG 1994;107:460-71.

5. Sundaresan S, Trachiotis GD, Aoe M, Patterson GA, Cooper JD. Donor lung procurement: assessment and operative technique. Ann Thorac Surg 1993;56:140913.

6. Pasque MK, Cooper JD, Kaiser LR, Haydock DA, Triantafillou AN, Trulock EP. Improved technique for bilateral lung transplantation: rationale and initial clinical experience. Ann Thorac Surg 1990;49:785-91.

7. Calhoon JH, Grover FL, Gibons WJ, et al. Single lung transplantation: alternative indications and technique. J Thorac Cardiovasc Surg 1991;101:816-25.

8. Lima O, Cooper JD, Peters WJ, et al. Effects of methylprednisolone and azathioprine on bronchial healing following lung autotransplantation. J THORAC Cardiovasc Surg 1982;83:418-21.

9. Morgan E, Lima O, Goldberg M, Ayabe H, Ferdman A, Cooper JD. Improved bronchial healing in canine left lung reimplantation using omental pedicle wrap. $\mathbf{J}$ Thorac Cardiovasc Surg 1983;85:134-9.

10. Goldberg M, Lima O, Morgan E, et al. A comparison between cyclosporin $\mathrm{A}$ and methylprednisolone plus azathioprine on bronchial healing following canine lung autotransplantation. J THORAC CARDIOvasC SURG 1983;85:821-6.

11. Toronto Lung Transplant Group. Unilateral lung transplantation for pulmonary fibrosis. N Engl J Med 1986;314:1140-5.

12. Shafers HJ, Haverich A, Wagner TOF, Wahlers $\mathrm{T}$, Alken A, Borst HG. Decreased incidence of bronchial complications following lung transplantation. Eur J Cardiothorac Surg 1992;6:174-9.

13. Miller JD, DeHoyos A, for the University of Toronto and Washington University Lung Transplant Programs. An evaluation of the role of omentopexy and of early perioperative corticosteroid administration in clinical lung transplantation. J THORAC CARdIOVASC SURG 1993;105:247-52.

14. Inui K, Schafers HJ, Aoki M, et al. Bronchial circulation after experimental lung transplantation: the effect of long-term administration of prednisone. J Thorac Cardiovasc Surg 1993;105:474-9.

15. Daly RC, Tadjkarimi S, Khaghani A, Banner NR, Yacoub MH. Successful double lung transplantation 
with direct bronchial artery revascularization. Ann Thorac Surg 1993;56:885-92.

16. Couraud L, Baudet E, Martigne C, et al. Bronchial revascularization in double lung transplantation: a series of 8 patients. Ann Thorac Surg 1992;53:88-94.

17. Daly RC, McGregor CGA. Routine immediate direct bronchial artery revascularization for single-lung transplantation. Ann Thorac Surg 1994;57:446-52.

18. Khaghani A, Tadjkarimi S, Al-Kattan K, et al. Wrapping the anastomosis with omentum or an internal mammary artery pedicle does not improve bronchial healing after single lung transplantation: results of a randomized clinical trial. J Heart Lung Transplant 1994;13:767-73.

19. Davis RD Jr, Trulock EP, Manley J, et al., and the Washington University Lung Transplant Group. Differences in early results after single-lung transplantation. Ann Thorac Surg 1994;58:1327-35.

20. Yokomise $\mathrm{H}$, Cardoso PFG, Kato $\mathrm{H}$, et al. The effect of pulmonary arterial flow and positive end-expiratory pressure on retrograde bronchial mucosal blood flow. J Thorac CARDIOvasc SurG 1991;101:201-8.

21. Fujimura S, Kondo T, Handa $M$, et al. Histologic assessment of bronchial anastomotic healing in canine lung transplantation. J Thorac Cardiovasc Surg 1987;94:323-30.

\section{Discussion}

Dr. Walter Klepetko. (Vienna, Austria). This paper summarizes the current status of a long and outstanding surgical development, which has brought the problem of bronchial anastomosis down from being the most crucial one in lung transplantation to the reported remarkable figure of $4 \%$. We all have to be indebted to the author's group and especially to Dr. Cooper and Dr. Patterson for their continuous work in the field.

It is fascinating to observe how the importance of several factors that were believed to be so crucial in the early period has changed. Lung transplantation without omental wrapping was considered previously to be simply impossible. Nowadays this technique is hardly used anymore. In addition, the former assumption that early postoperative use of steroids could severely compromise bronchial healing has been changed into the beneficial concept of immediate postoperative application of steroids quite uniformly.

This paper nicely demonstrates that healing of the airway depends on two major factors. Correct surgical technique is one of them. It is obviously less important which particular technique, end-to-end or telescope, is applied, as long as the surgeon has become experienced and familiar with it. It is also pointed out that not every technique should be applied in every anatomic situation. For instance, the telescoping technique in the presence of very small airways seems to be a poor option. On the other hand, adequate bronchial microcirculation plays a major role in prevention of bronchial problems and depends on a multitude of factors. This is shown nicely in this study by the fact that prolonged ventilation was associated with a higher prevalence of problems. Perioperative management, therefore, becomes crucial for microcirculation, and not the least important factor is efficient prevention, diagnosis, and treatment of rejection.

In our own experience of about 120 lung transplantations, the worst case of severe impairment of microcirculation occurred in a patient after BLT. At bronchoscopy, severe, almost complete, ischemia was present as far down as to the segmental bronchial orifices of the lower lobes. Despite the severity of the situation, we were able to treat the patient successfully with Y-shaped silicone stents extending into the upper lower lobe carina on the left and down the intermediate bronchus on the right side. After 6 months one stent was lost and the patient underwent successful retransplantation. The patient is still alive 4 years after that procedure.

In light of these considerations, I would like to ask the authors three questions. First, could they give us more details about their postoperative regimen of heparinization and prostaglandin $\mathrm{E}_{1}$ administration? Second, the authors mentioned in the manuscript that they are now accepting moderate doses of preoperative steroids. I would like to ask what they understand concerning the moderate dose and what the highest dose of steroids was that they ever accepted. Finally I would like to address a question to Alec Patterson. Looking back at the more than 10-year period during which the technique of bronchial anastomosis has significantly developed, what, in your opinion, was the initial benefit of omental wrapping? Was it simply a mechanical effect that prevented catastrophe or was it truly beneficial for the bronchial microcirculation?

Dr. Date. In the early several cases we used low-dose heparin systemically, but in the rest of the cases we used low-dose heparin, 5000 units every 12 hours, subcutaneously, to prevent thrombotic complications after the operation. We currently use prostaglandin $E_{1}$ routinely, unless significant hypotension becomes a problem.

Concerning preoperative use of steroids, we currently accept up to $20 \mathrm{mg}$ prednisone daily. On occasion patients require acute augmentation of steroid therapy because of an exacerbation of the underlying disease. We still accept these patients, expecting that they are at increased risk of poor bronchial healing.

Dr. Alec G. Patterson (St. Louis, Mo.). I would like to initially congratulate Dr. Date for a great presentation and Dr. Klepetko for his kind remarks. For those of you who do not know, Dr. Klepetko has developed and now directs one of the most successful lung transplant programs in Europe.

I do not know precisely what the benefit of omental wrapping was in those early days, although I think it had two important benefits. First, it revascularized the ischemic bronchus. Dr. Joel Cooper showed that nicely in a series of canine experiments years ago. I also think that it provided security and protection from mediastinal sepsis in those few patients who did have some bronchial dehiscence. In those days the preservation that we used was terrible. We purposely made the donor lung atelectatic, heparinized the donor, removed the lung without the use of any flushing solution, kept it immersed in cold saline solution, and then placed it in the recipient while making 
no attempt to keep it cold during the suturing. Given that, it is remarkable to me that any of those transplants worked, and it is no surprise that the donor pulmonaryto-bronchial collateral circulation was deficient in some of those cases.

Dr. Hans-Joachim Schäfers (Hannover, Germany). The current prevalence of airway complications, in the range of $4 \%$, certainly indicates that one of the major arguments of isolated lung transplantation versus heart-lung and domino transplantation is now an argument of the past. In a similar time frame, since 1988 up to the beginning of this year, we have in our lung transplant program done a total of 140 isolated lung transplants. We have observed airway complications in 13 of 210 anastomoses at risk, for a prevalence of $6.2 \%$. Initially the prevalence was rather high, which prompted us to institute a protocol directed at improving bronchial microcirculation. This was indicated by experimental data, part of which was presented at the meeting of this Society 3 years ago. The patients were given steroids, heparin, and prostacyclin beginning in the immediate postoperative phase. In addition, as suggested by the San Antonio group, donor and recipient airways were kept short, which allowed us to omit omentopexy. End-to-end anastomosis with simple interrupted sutures has been the main approach, with telescoping of the bronchi used only for size discrepancy.

Following this concept, we have observed a prevalence of airway complications of only $4 \%$, that is, 8 complications in the most recent 198 grafts at risk. We have, interestingly, observed a change in the type of complications. Rather than having ischemia right at the site of the anastomosis, we have had problems limited to the lobar bronchi, especially the intermediate bronchus. If one excludes those isolated lobar complications, the prevalence would only be $2.5 \%$.

In the past 2 years we have used parenchyma-sparing resection for the treatment of stenosis rather than stenting. The results have been excellent in the most recent 4 patients.

My questions to the authors are as follows. Have they had a similar trend of ischemia occurring not so much on the anastomotic site itself but extending especially into the intermediate bronchus? Do they have any experience with resection of bronchial stenosis? Finally, what do they think the reasons are for the higher prevalence of airway complications in SLT?

Dr. Date. We have also seen several patients in whom stenotic changes developed within the bronchus intermedius. These have been difficult to treat with conventional silicone-rubber stents. We have also seen malacia with intact mucosa. In these patients we have used a selfexpandable metallic stent instead of a silicone-rubber stent and are pleased with the results. We have not used surgical resection to correct bronchial stenosis.

As concerns the reason SLT is associated with more complications than BLT, it is possible that the collateral circulation in the parenchyma of the SLT is not as good as that of the BLT. We have observed that, as a result of allograft dysfunction, the postoperative course of SLT for fibrosis or pulmonary hypertension is more complicated than that for BLT. BLT has theoretically a twofold risk of airway complication; however, if we calculate the airway complication per anastomosis, we find that SLT does have more complications than BLT. 